\title{
TALIP Perspectives
}

This is the first in what I hope will be an ongoing series of editorials entitled "TALIP Perspectives". These will be modeled loosely on Computational Linguistics' "Last Words" section, which has been active since 2005. As I noted in my welcome editorial in the 12(3) issue, the goal of this section is to promote "discussion of topics that link speech and language technology to issues of broader social interest with a focus on the Asian arena." The hope is that we will have a short (maximum four page) editorial appropriate for this forum once every couple of issues, and I hereby reissue my invitation to anyone who wants to contribute an editorial to contact me directly with a proposal. Submissions will be shared with the Associate Editors for discussion. In rare instances, if the submission involves substantial technical content, we will ask an outside reviewer for assistance.

By a happy coincidence one issue that has come up recently relates to the ACM, TALIP and the portrayal of scientific results in the popular science press-a topic that is of a great deal of personal interest to me, and one that should properly be the interest of anyone working in science and engineering. Back in late July 2013, I was informed, as editor of TALIP, of the ACM's desire to promote its journals more widely, and I was requested to inform the ACM's Public Relations department of "any outstanding or unusual articles that could be made into short newsworthy items."

This is, of course, very appropriate since one of the important functions of a professional society is the promotion, in the public view, of scientific progress in its domain. It is also extremely timely: As anyone who reads the popular science press will know, much of what becomes widely visible as scientific "progress" is controlled by the so-called "prestige" journals, namely, Science, Nature, and their ilk, with publication in a venue like Science often leading to wide coverage in the popular press.

But as many have argued, this has led to a crisis in scientific publishing. Citing work by Björn Brembs, Katherine Button and Marcus Munafô [Brembs et al. 2013], Curt Rice, Pro Rector for Research \& Development at the University of Troms $\varnothing$ notes a particularly disturbing finding that "the most prestigious journals have the highest rates of retraction, and that fraud and misconduct are greater sources of retraction in these journals than in less prestigious ones" [Rice 2013]. He goes on to argue the following:

"Among articles that are not retracted, there is evidence that the most visible journals publish less reliable (in other words, not replicable) research results than lower ranking journals. This may be due to a preference among prestigious journals for results that have more spectacular or novel findings, a phenomenon known as publication bias."

These observations are consistent with my own (e.g., Sproat [2010]) and those of other linguists (e.g., Liberman [2011]) about the poor quality of articles on language that get published by such venues as Science, which often involve flashy-looking techniques that appear to yield stunning results-perfect fodder for the popular science pressbut which do not hold up under even mild scrutiny by informed experts.

It is thus welcome that professional societies such as the ACM are making an effort to promote work submitted to their journals. First of all, the editorial board of ACM journals such as TALIP know papers in their field far better than the editors of a

(C) 2013 ACM 1530-0226/2013/10-ART13 $\$ 15.00$

DOI : http://dx.doi.org/10.1145/2523057.2523058 
generalist publication like Science ever could. While it is certainly possible that a flawed article could still get published, we can be sure that articles published in a venue such as this one will be thoroughly reviewed by experts deeply knowledgeable about the technical area of the article. Second, while publicity is often welcome, it is not a motivating force as it apparently is when editors of Science decide on an article's potential "impact". No article will ever be accepted to TALIP merely because it will increase the "impact" of the journal or because it will result in a nice write-up in the science section of the New York Times.

That said, and in keeping with the ACM's request, I will be on the lookout for articles accepted to TALIP that would make a good writeup in the Times and other press publications. If I see something that looks potentially newsworthy, I will discuss that article with the Associate Editor who is in charge of it, and then, if we both agree that it would be good to promote it, I will work with the ACM Editorial Office on a press release for the ACM Public Relations department.

A journal like TALIP cannot hope to compete in the popular press with a "prestige" publication like Science: diets rich in fiber and protein and low in sugars and fats often have a tough time competing with the processed food industry whose products have greater mass appeal. But by injecting some solid if perhaps less "exciting" results into the mix, we may hope to balance things out just a little better.

\section{REFERENCES}

Björn Brembs, Katherine Button, and Marcus Munafò. 2013. Deep impact: Unintended consequences of journal rank. Frontiers Human Neurosci. 24 June, 2013.

http://www.frontiersin.org/Human_Neuroscience/10.3389/fnhum.2013.00291/abstract.

Curt Rice. 2011. Science research: Three problems that point to a communications crisis. The Guardian, Higher Education Network, 11 February, 2013. http://www.theguardian.com/higher-education-network /blog/2013/feb/11/science-research-crisis-retraction-replicability.

Mark Liberman. 2011. Phonemic diversity decays "out of Africa”? Language Log, University of Pennsylvania. http://languagelog.ldc.upenn.edu/nll/?p=3090.

Richard Sproat. 2010. Last words: Ancient symbols, computational linguistics, and the reviewing practices of the general science journals. Computat. Linguistics 36, 3.

Richard Sproat

Editor-in-Chief

The views expressed in this editorial are those of the author and do not necessarily reflect the views or policy of the Association for Computing Machinery. 